\title{
ETHANOL INDUCES IL-6 AND TNF- $\alpha$ CYTOKINE AND iNOS AND COX-2 ENZYME GENE EXPRESSION IN 3T3-L1 PREADIPOCYTES
}

\author{
Kiselova-Kaneva Y., O. Tasinov, D. Vankova, D. Ivanova \\ Department of Biochemistry, Molecular Medicine and Nutrigenomics, \\ Laboratory of Nutrigenomics, Functional Foods and Nutraceuticals, \\ Medical University of Varna
}

\begin{abstract}
It is known that alcohol influences on human health and its effects are widely studied. Adipose tissue (AT) may be an important target of ethanol action. Data about the effect of ethanol on cytokine and pro-inflammatory enzymes' gene expression in adipocytes are scarce. The aim of the present study was to establish its effect on transcription of inflammatory markers IL-6, TNF- $\alpha$, COX-2 and iNOS in cultured 3T3-L1 cells. MTT test was performed in order to determine ethanol effect on cell viability. Expression of selected genes was measured using two step quantitative PCR. Results were analyzed using $2^{-\Delta \Delta \mathrm{Ct}}$ method. Exposure of 3T3-L1 cells to increasing ethanol concentrations $(0,125 \%-0,625 \%)$ resulted in gradual cell viability decline. Expression of all the genes studied was up-regulated upon ethanol treatment. In cells treated with $0,5 \%$ ethanol, there was a 4,8- $(p<0,001), 6,3-(p<0,001), 5,5-(p<0,05)$ and 3,6- $(p<0.05)$ fold increase of mRNA levels of IL-6, TNF- $\alpha$, iNOS and COX-2, respectively, as compared with untreated controls. mRNA levels of the respective genes highly correlated with the applied ethanol concentration. In conclusion, our results show that ethanol treatment may increase the inflammatory potential of AT up-regulating expression of inflammatory cytokines IL-6 and TNF- $\alpha$ and inflammatory enzymes iNOS and COX-2 on transcription level.
\end{abstract}

Key words: ethanol, 3T3-L1, IL-6, TNF- $\alpha$, COX-2, iNOS

\section{INTRODUCTION}

It is known that alcohol influences on human health and its effects are widely studied. Deleterious consequences from excessive consumption are associated with elevated morbidity and mortality. Other studies have demonstrated that moderate alcohol consumption may improve human health, especially in regard of cardiovascular diseases (12). Additionally, alcohol application for amelioration of certain inflammatory conditions is a popular practice in folk medicine. This may be attributed to its ability to interfere with molecular mechanisms underlying inflammatory response in variety of cell types. A number of experimental data in vitro and in vivo demonstrates that ethanol can act as anti-inflammatory agent diminishing the ability of different stimuli, such as bacterial lipopolysaccharides to up-regulate the expression of the inflammatory cytokines IL- 6 and TNF- $\alpha$ (8) and iNOS (18). However, when applied in the absence of inflammatory stimuli ethanol induces produc-

\footnotetext{
Address for correspondence:

Y. Kiselova-Kaneva, Dept. of Biochemistry, Molecular Medicine and Nutrigenomics, Laboratory of Nutrigenomics, Functional Foods and Nutraceuticals, Medical University of Varna 55 Marin Drinov Str., Varna 9002, Bulgaria

Tel: +3595267750/ext. 2651; Mobile: +359896041419

e-mail: ykisselova@abv.bg
}

tion of pro-inflammatory cytokines IL-6 and TNF- $\alpha$ and of the inflammatory enzymes iNOS and COX-2 $(14,21)$.

Adipose tissue (AT) may be an important target of ethanol action. Few publications focus on that. In human primary adipose cell line, Wandler et al. (2008) establish a complex time-dependent change in IL-6 release after ethanol treatment, where protein levels recover to initial state after a fall $1,5 \mathrm{~h}$ after treatment. In vivo chronic ethanol consumption increases IL- 6 and TNF- $\alpha$ levels in rat AT (11). In man, increased IL- 6 and TNF- $\alpha$ levels in AT correlate with alcohol-induced liver injury (15).

Data about the effect of ethanol on cytokine and pro-inflammatory enzymes' gene expression in adipocytes are scarce. Pre-adipocytes along with mature adipocytes, fibroblasts and macrophages, the cell types found in AT, actively participate in AT secretory function (9), thus participating in whole body metabolism by secretion of a variety of adipokines.

TNF- $\alpha$ and IL- 6 are among the numerous pro-inflammatory factors constitutively expressed in AT (3). Increased IL- 6 and TNF- $\alpha$ levels are regarded as a hallmark of chronic inflammation accompanying obesity and preceding metabolic diseases such as insulin resistance, type 2 diabetes mellitus, atherosclerosis and cardiovascular disease (4). Originally identified as a macrophage product, TNF- $\alpha$ was the first AT-secreted product proposed to represent a 
molecular link between obesity and insulin resistance (10). IL-6 is considered to be a stress-induced cytokine with varying effects on a variety of tissues. As an inflammatory mediator IL-6 stimulates acute phase protein synthesis (19). As much as one third of total circulating IL-6 concentrations originate from AT (7) and its plasma concentration highly correlates with body mass and inversely to insulin sensitivity (2). iNOS is the inducible isoform of the enzyme producing NO, which is an important mediator of many processes, including inflammation. Its expression may be induced by stimuli such as lipopolysaccharides (17). COX-2 is the rate-limiting enzyme in production of a range of local mediators involved in various of processes, including local inflammation.

As AT in obesity is implicated in low grade inflammation, investigations of the effects of ethanol on the expression of cytokines and inflammatory enzymes in cultured preadipocytes could help formulating new diet and social behavior recommendations to combat obesity.

\section{MATERIAL AND METHODS}

\section{Cell culture}

3T3-L1 cells were obtained from the American Type Culture Collection (ATCC). Preadipocytes were cultured in $75 \mathrm{~cm}^{2}$ flasks at $37^{\circ} \mathrm{C}$ in a humidified chamber with $5 \%$ $\mathrm{CO}_{2}$ atmosphere. Nutrient medium comprised phenol red-containing Dulbecco's modified Eagle's medium (DMEM, Lonza) with 4,5 g/L glucose, L-glutamine and supplemented with fetal bovine serum (FBS, Sigma-Aldrich) to final concentration of $10 \%$ and penicillin/streptomycin mixture to final concentration of $100 \mathrm{U} / \mathrm{mL}$ each.

\section{Cytotoxicity assay}

Viability of ethanol-treated cells was evaluated using the 3-(4,5-dimethylthiazol-2-yl)-2,5-diphenyltetrazolium bromide (MTT). The assay was based on the ability of viable cells to reduce the yellow MTT to purple insoluble formazan. Briefly $100 \mu \mathrm{L}$ of MTT solution in PBS $(\mathrm{pH}=7,4)$ at concentration of $2 \mathrm{mg} / \mathrm{mL}$ was added to each well. After a 4-h incubation of the plates at dark the medium was removed and $1 \mathrm{~mL}$ of DMSO was added to each well to lyse the cells and dissolve the reduced MTT. After thorough mixing, 200 $\mu \mathrm{L}$ were transferred to 96 plates and the absorbance at $\lambda_{\max }=550 \mathrm{~nm}$ was determined using Synergy 2 plate reader (BioTek). Viability of treated cells was presented in percentage of the viability of the non-treated cells, which is considered $100 \%$. All the treatments were performed in triplicate. Data were presented as mean $\pm \mathrm{SD}$.

\section{Experimental procedure}

Cells were collected and seeded in 6 well flasks at density $2 \times 10^{5}$ cells/well. After overnight incubation cells were treated with ethanol in different concentrations and dissolved in phenol red free DMEM (Lonza) without any sup- plements. Cells were incubated either $20 \mathrm{~h}$-long for MTT test, or $24 \mathrm{~h}$-long for gene expression determination when RNA was isolated from harvested cells.

\section{Gene expression analysis}

Two-step real-time PCR analysis was performed to estimmate gene expression level in cultured cells.

RNA isolation

Total RNA isolation was performed with Tri reagent (Ambion) following the manufacturer's protocol.

Reverse transcription

RNA (20-100 ng) was reversely transcribed with Revertaid ${ }^{\mathrm{TM}}$ First Strand cDNA Synthesis Kit (Fermentas) containing oligo (dT)18 primer and RevertAid ${ }^{\mathrm{TM}}$ reverse transcriptase. cDNA synthesis was performed on Gene Amp PCR 7500 thermal cycler (Applied Biosystems). Reaction conditions in final volumes of $10 \mu \mathrm{L}$ were provided according to the manufacturer's guidelines. cDNA was dissolved after synthesis by adding of $30 \mu \mathrm{L}$ nuclease-free distilled water (Fermentas) to each sample.

Quantitative real- time PCR

Primers (Table 1) were designed using real-time PCR Gene Expression Design Tool (http://eu.idtdna.com/Scitools/Applications/RealTimePCR/Defaultaspx) and commercially synthesized (Alpha DNA, Canada). As a template for real-time PCR $0,39 \mu \mathrm{L}$ of cDNA was amplified in $5 \mu \mathrm{L}$ final volume. Final primers' concentration was $300 \mathrm{nM}$. Analysis of the gene expression was performed using GreenMasterMix (Genaxxon) containing Eva Green fluorescent dye. Reactions were performed in 96 well plates. Reaction parameters were the following: enzyme activation and denaturation at $95^{\circ} \mathrm{C} / 10 \mathrm{~min}$, amplification at $95^{\circ} \mathrm{C} / 15$ sec, annealing at $60^{\circ} \mathrm{C} / 1 \mathrm{~min}, 40$ cycles. Analysis was performed on ABI PRISM 7500 (Applied Biosystems).

Gene expression levels were calculated using the $2^{-\mathrm{MAC}}$ method (13) and expressed as relative units (RU) compared to the untreated controls where the level of gene expression of interest was considered to be equal to 1 . Results were presented as mean of the RU \pm SEM. Beta-actin was used as endogenous control. Amplification products were examined for nonspecific amplification by including an additional denaturation step in the real-time thermal cycler protocol. All the measurements were performed at least in triplicate.

\section{Statistical analysis}

Statistical analyses were performed using Microsoft Excell Office 2007 software. Differences between two groups were analyzed by unpaired two-tailed Student's $t$-tests. A $p$ value less than 0,05 was considered significant.

\section{RESULTS}

\section{Ethanol cytotoxicity in 3T3-L1 cells}

Exposure of 3T3-L1 cells to increasing ethanol concentrations $(0,125 \%-0,625 \%)$ resulted in gradual cell viability diminution (Fig. 1). 


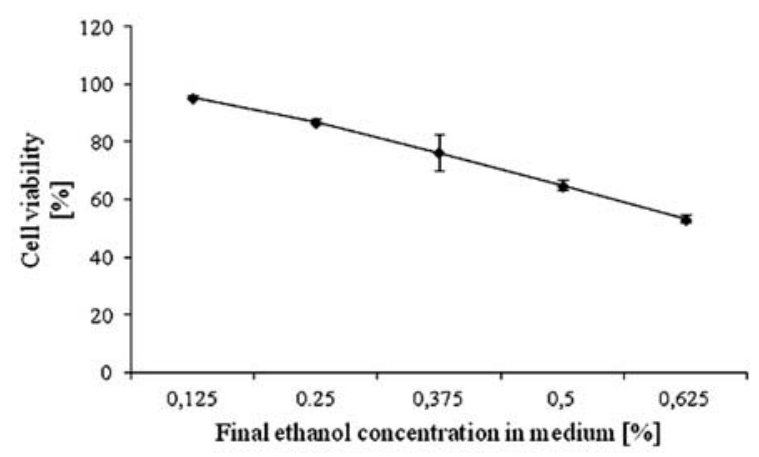

Fig. 1. Effect of ethanol on cell viability. Cells were treated with ethanol in concentration range of 0,125-0,625\%. Data are presented as mean $\pm S D$

Ethanol-induced IL-6 and TNF- $\alpha$ cytokine gene expression in 3T3-L1 cells

Ethanol applied on 3T3-L1 preadipocytes enhanced IL-6 gene expression (Fig. 2). Final ethanol concentration of $0,25 \%$ stimulated transcription of IL- 6 gene by $44 \%$ $(p<0,01)$ and that one of $0,5 \%$ - even by $480 \%(p<0,001)$ as compared to untreated controls. Twofold increase of ethanol concentration (from $0,25 \%$ to $0,5 \%$ ) enhanced the gene expression levels by more than three times $(\mathrm{p}<0,001)$ representing a concentration-dependent manner of action.

TNF- $\alpha$ gene expression was also up-regulated upon ethanol treatment (Fig. 3). Ethanol concentrations of $0,125 \%$ and $0,25 \%$ increased mRNA levels by $54 \%(\mathrm{p}=0,015)$ and $71 \%(\mathrm{p}<0,05)$, respectively. The highest concentration of ethanol (of $0,5 \%$ ) increased by more than six times TNF- $\alpha$ gene transcription as compared to untreated controls $(p<0,001)$. While no difference was established between the effect of the lower concentrations $(0,125 \%$ and $0,25 \%)$, the twofold elevation of ethanol concentration from $0,25 \%$

Table 1. Primer sequences of the investigated genes used in the quantitative Real-Time PCR analysis.

\begin{tabular}{|c|c|}
\hline gene & Nucleotide sequence (5'-3') \\
\hline $\begin{array}{l}\beta \text {-Actin } \\
\text { Forward } \\
\text { Reverse }\end{array}$ & $\begin{array}{l}\text { ACGGCCAGGTCATCACTATTG } \\
\text { CAAGAAGGAAGGCTGGAAAAG }\end{array}$ \\
\hline $\begin{array}{l}\text { IL-6 } \\
\text { Forward } \\
\text { Reverse }\end{array}$ & $\begin{array}{l}\text { GAGTTGTGCAATGGCAATTCTGG } \\
\text { CAAGTGCATCATCGTTGTTCAT }\end{array}$ \\
\hline $\begin{array}{l}\text { TNF- } \alpha \\
\text { Forward } \\
\text { Reverse }\end{array}$ & $\begin{array}{l}\text { CCCTCACACTCAGATCATCTTCT } \\
\text { GCTACGACGTGGGCTACAG }\end{array}$ \\
\hline $\begin{array}{l}\text { iNOS } \\
\text { Forward } \\
\text { Reverse }\end{array}$ & $\begin{array}{l}\text { GGCAGCCTGTGAGACCTTTG } \\
\text { GCATTGGAAGTGAAGCGTTTC }\end{array}$ \\
\hline $\begin{array}{l}\text { COX-2 } \\
\text { Forward } \\
\text { Reverse }\end{array}$ & $\begin{array}{l}\text { TGAGCAACTATTCCAAACCAGC } \\
\text { GCACGTAGTCTTCGATCACTATC }\end{array}$ \\
\hline
\end{tabular}

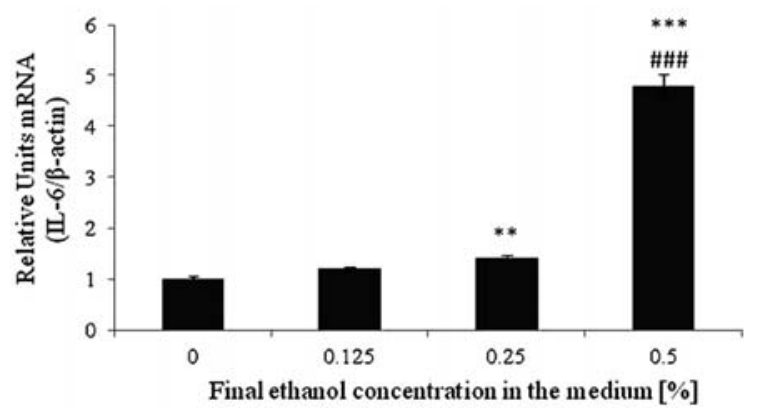

Fig. 2. IL-6 expression levels in 3T3-L1 preadipocytes after ethanol treatment in concentrations of $0,125 \%$, $0,25 \%$ and $0,5 \%$. Data are presented in RU SEM vs $\beta$-actin as endogenous control ${ }^{* *} p<0,01 ;{ }^{* *} p<0,001$ vs controls $(0 \%) ;{ }^{\# \#} p<0,001$ - compared to
$0,25 \%$

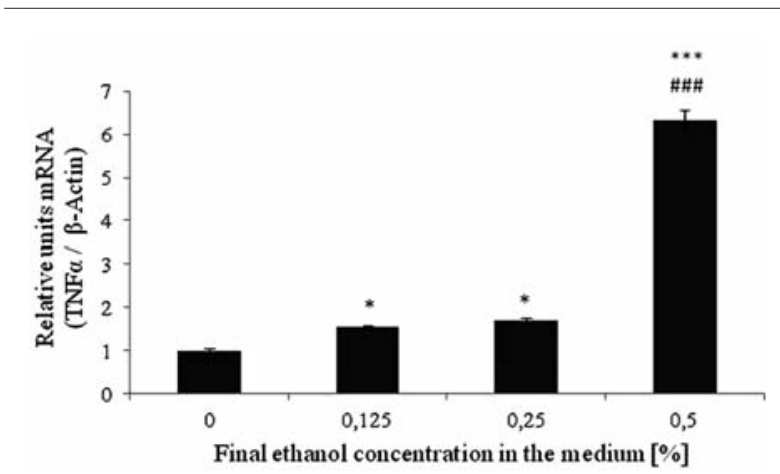

Fig. 3. TNF- $\alpha$ expression levels in 3T3-L1 preadipocytes after ethanol treatment in concentrations of $0,125 \%, 0,25 \%$ and $0,5 \%$. Data are presented in $R U \pm S E M$ vs $\beta$-actin as endogenous control ${ }^{*} p<0,05 ;{ }^{* * *} p<0,001$ vs controls $(0 \%) ;{ }^{*}{ }_{p<0,001}$ - compared to $0,25 \%$

up to $0,5 \%$ resulted in an about 3,7-fold increase of TNF- $\alpha$ mRNA levels $(\mathrm{p}<0.001)$. mRNA levels of the respective genes highly correlated with the applied ethanol concentration $(r=0,92$ for IL- 6 and $r=0,93$ for TNF- $\alpha$ ).

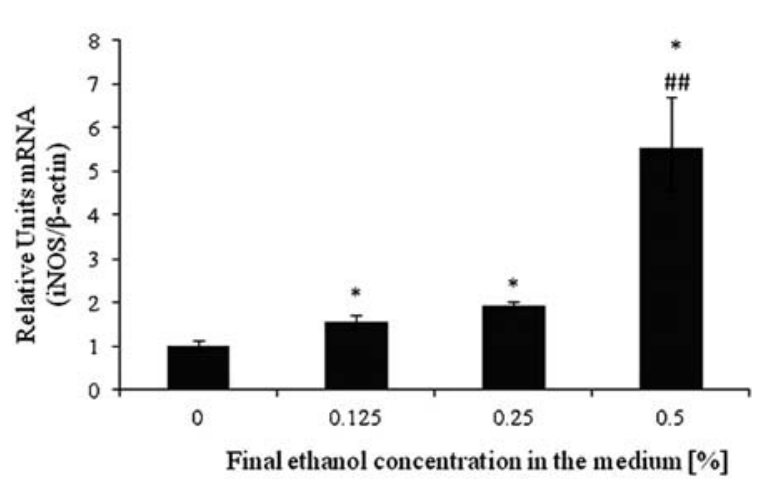

Fig. 4. iNOS expression levels in 3T3-L1 preadipocytes after ethanol treatment in concentrations of $0,125 \%$, $0,25 \%$ and $0,5 \%$. Data are presented in $R U \pm S E M v s$ $\beta$-actin as endogenous control ${ }^{*} p<005$ vs controls (0\%); ${ }_{p<0,01}$ - compared to $0,25 \%$ 
Ethanol-induced iNOS and COX-2 enzyme gene expression in 3T3-L1 cells

Similarly as with IL- 6 and TNF- $\alpha$ cytokine gene expression, ethanol treatment stimulated iNOS and COX-2 enzyme transcription levels.

After 3T3-L1 cell exposure to increasing ethanol concentrations, iNOS mRNA levels were higher than those in untreated controls by $57 \%, 95 \%$ and $554 \%$, respectively $(p<0,05)$ (Fig. 4). Twofold increase of ethanol concentration (from $0,25 \%$ to $0,5 \%$ ) increased iNOS mRNA levels by three times $(\mathrm{p}<0,01)$.

Transcription of COX-2 in 3T3-L1 preadipocytes was stimulated upon ethanol treatment, too (Fig. 5).

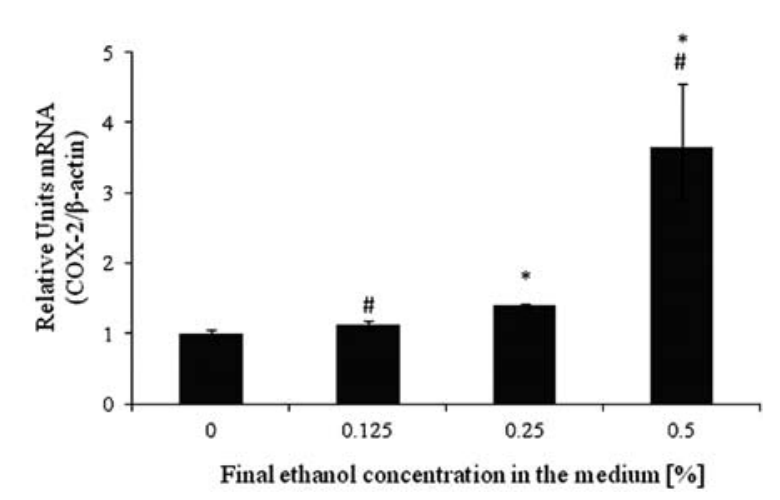

Fig. 5. COX-2 expression levels in 3T3-L1 preadipocytes after ethanol treatment in concentrations of $0,125 \%, 0,25 \%$ and $0,5 \%$. Data are presented in $R U \pm S E M$ vs $\beta$-actin as endogenous control ${ }^{*} p<0,05$ vs controls (0\%); ${ }^{*} p<0,05$ - compared to $0,25 \%$

Ethanol in concentrations of $0,125 \%, 0,25 \%$ and $0,5 \%$ increased mRNA levels by $13 \%, 40 \%(\mathrm{p}<0,01)$ and $365 \%$ $(p<0,05)$, respectively as compared to untreated controls. Its twofold increase resulted in higher mRNA levels by $24 \%(0,125 \%$ vs $0,25 \% ; p<0,05)$ and by $260 \%(0,25 \%$ vs $0,5 \% ; p<0,05)$, respectively. mRNA levels correlated with ethanol concentration ( $r=0,95$ for iNOS and $r=0,93$ for COX-2).

\section{DISCUSSION}

The present study demonstrates for the first time data about the stimulatory effect of ethanol on IL- 6 and TNF- $\alpha$ cytokines and COX-2 and iNOS pro-inflammatory enzymes expression in cultured 3T3-L1 preadipocytes on transcriptional level after $24 \mathrm{~h}$ exposure to different ethanol concentrations.

The volumetric ethanol concentrations of $0,125 \%, 0,25 \%$ and $0,5 \%$ selected by us correspond to $21,4 \mathrm{mM}, 42,8 \mathrm{mM}$ and $85,6 \mathrm{mM}$ ethanol, respectively, and are physiologically relevant in vivo (5). Furthermore, cytotoxicity MTT test proves a gradual diminution of cell viability in the chosen ethanol concentration range (Fig. 1).

Ethanol up-regulated the expression of IL- 6 and TNF- $\alpha$ in 3T3-L1 preadipocytes and mRNA levels of the respective genes highly correlated with the applied ethanol concentration. The results of the present study are in accordance with data available from in vitro investigations of other types of cultured cells. For example, increased IL- 6 and TNF- $\alpha$ expression has been established in response to ethanol treatment in mouse RAW 264.7 macrophages (6). Very few studies dealing with ethanol effects on AT or (pre)adipocytes are available. In vivo rat model experiments have established increased IL- 6 and TNF- $\alpha$ in AT of animals chronically administered ethanol (11). A time-dependent change of IL- 6 release after ethanol treatment has been observed in human primary adipose cells (20). We have found out that ethanol treatment in concentrations of $0,125 \%, 0,25 \%$ and $0,5 \%$ up-regulates gene expression in a concentration-dependent manner. Besides, we have established a reliable correlation for both IL- 6 and TNF- $\alpha$ mRNA levels.

We find out a significantly induced expression of a second set of inflammatory markers, i.e. COX-2 and iNOS upon treatment with ethanol, too, and mRNA levels highly correlated with ethanol concentrations. Similarly, physiologically relevant concentrations of ethanol (of $50 \mathrm{mM}$ ) activate expression of iNOS and COX-2 in murine RAW 264.7 macrophages (6). Data from this study provide evidence that ethanol may enhance the inflammatory potential of 3T3-L1 preadipocytes by increasing the expression of inflammatory markers. The effect of ethanol on cytokine and inflammatory enzyme gene expression could be attributed to its ability to modify signaling pathways. Transcription of IL-6 and TNF- $\alpha$ and inflammatory enzymes COX-2 and iNOX is mediated by NF-kB (1). It has been shown that NF-kB activity and transcription are increased after ethanol treatment (5). As a transcription factor NF-kB is a target of multiple signaling pathways, including Toll-like Receptors (TLRs) mediated signalization. It has been demonstrated that the effect of ethanol on TNF- $\alpha$, COX-2 and iNOS production is mediated by TLR (6). As both adipocytes and preadipocytes express a broad set of TLRs (16), they could respond to specific stimulation by cytokine production. Further investigations of ethanol effects on other molecules involved in these signal pathways, especially in AT, would elucidate the mechanisms of ethanol pro-inflammatory action.

\section{CONCLUSIONS}

Our present study undoubtedly shows that ethanol may increase the inflammatory potential of AT up-regulating expression of inflammatory cytokines IL- 6 and TNF- $\alpha$ and inflammatory enzymes iNOS and COX-2 on transcription level.

\section{REFERENCES}

1. Ahn, K., B. Aggarwal. Transcription factor NF-kappaB: a sensor for smoke and stress signals.Ann. N. Y. Acad. Sci., 1056, 2005, 218-233. 
2. Bastard, J. P., C. Jardel, E. Bruckert, P. Blondy, J. Capeau, M. Laville, et al. Elevated levels of interleukin 6 are reduced in serum and subcutaneous AT of obese women after weight loss.- J. Clin. Endocrinol. Metab., 85, 2000, No 9, 3338-3342.

3. Coppack, S. W. Pro-inflammatory cytokines and adipose tisue.- Proc. Nutr. Soc., 60, 2001, No 3, 349-356.

4. Dandona, P, A. Aljada, A. Bandyopadhyay. Inflammation: the link between insulin resistance, obesity and diabetes.- Trends Immunol., 25, 2004, No 1, 4-7.

5. Davis, R. L., P. J. Syapin. Acute ethanol exposure modulated expression of inducible nitric-oxide synthase in human astroglia: evidence for a transcriptional mechanism.- Alcohol, 32, 2004, No 3, 195-202.

6. Fernandez-Lizarbe, S., M. Pascual, M. Soledad Gascon, A. Blanco, C. Guerri. Lipid rafts regulate ethanol-induced activation of TLR4 signaling in murine macrophages.- Mol. Immunol., 45, 2008, No 7, 2007-2016.

7. Frühbeck, G., J. Gómez-Ambrosi, F. J. Muruzábal, M. A. Burrell. The adipocyte: a model for integration of endocrine and metabolic signaling in energy metabolism regulation.- Am. $J$. Physiol. Endocrinol. Metab., 280, 2001, No 6, E827-E847.

8. Goral, J., E. J. Kovacs. In vivo ethanol exposure down-regulates TLR2-, TLR4-, and TLR9-mediated macrophage inflammatory response by limiting p38 and ERK1/2 activation.- J. Immunol., 174, 2005, No $1,456-463$.

9. Guerre-Millo, M. Adipose tissue and adipokines: for better or worse.- Diabetes Metab., 30, 2004, No 1, 13-19.

10. Hotamisligil, G. S. Molecular mechanisms of insulin resistance and the role of the adipocyte.- Int. $J$. Obes. Relat. Metab. Disord., 24, 2000, No 4, S23-27.

11. Kang, L., B. Sebastian, M. Pritchard, B. Pratt, S. Previs, L. Nagy. Chronic ethanol-induced resistance is associated with macrophage infiltration into AT and altered expression of adipocytokines.- Alcohol. Clin. Exp. Res., 31, 2007, No 9, 1581-1588.

12. Klatsky, A. L., N. Udaltsova. Alcohol drinking and total mortality risk.- Ann. Epidemiol., 17, 2007, No 5, S63-S67.

13. Livak, K. J., T. D. Schmittgen. Analysis of relative gene expression data using real-time quantita- tive PCR and the 2- ${ }^{\Delta \Delta C(\mathrm{~T})}$ method.- Methods, 25, 2001, No 4, 402-408.

14. Nanji, A. A, L. Miao, P. Thomas, A. Rahemtulla, S. Khwaja, S. Zhao, et al. Enhanced cyclooxygenase-2 gene expression in alcoholic liver disease in the rat.- Gastroenterology, 112, 1997, No 3, 943-951.

15. Naveau, S., A. M. Cassard-Doulcier, M. Njiké-Nakseu, L. Bouchet-Delbos, N. Barri-Ova, H. Boujedidi, et al. Harmful effect of adipose tissue on liver lesions in patients with alcoholic liver disease.- J. Hepatol., 52, 2010, No 6, 895-902.

16. Pietsch, J., A. Batra, T. Stroh, I. Fedke, R. Glauben, B. Okur, et al. Toll-like receptor expression and response to specific stimulation in adipocytes and preadipocytes.- Ann. N. Y. Acad. Sci., 1072, 2006, 407-409.

17. Suliburk, J., S. West, D. Mercer. Lipopolysacharide (LPS)-induced iNOS expression and gastric injury: role for prostaglandins (PGs).- $J$. Am. Coll. Surg, 199, 2004, Suppl. 3, 23-24.

18. Syapin, P. J., J. D. Militante, D. K. Garrett, L. Ren. Cytokine-induced iNOS expression in C6 glial cells: transcriptional inhibition by ethanol.- J. Pharmacol. Exp. Ther., 298, 2001, No 2, 744-752.

19. Trayhurn, P., I. S. Wood. Adipokines: inflammation and pleiotropic role of white adipose tissue.Br. J. Nutr., 92, 2004, No 3, 347-355.

20. Wandler, A., J. Bruun, M. P. Nielsen, B. Richelsen. Ethanol exerts anti-inflammatory effects in human adipose tissue in vitro.- Mol. Cell. Endocrinol., 296, 2008, No 1-2, 26-31.

21. Yuan, G. J., X. R. Zhou, Z. J. Gong, P. Zhang, X. M. Sun, S. H. Zheng. Expression and activity of inducible nitric oxide synthase and endothelial nitric oxide synthase correlate with ethanol-induced liver injury.- World J. Gastroenterol., 12, 2006, No 15, 2375-2381.

\section{Acknowledgements}

This study was partially supported by Medical Research Fund of the Medical University of Varna, Bulgaria, Ministry of Education, Science and Youth (Grant No WU-L-320/2007) and by COST action BM0602: Adipose tissue: a key target for prevention of the metabolic syndrome funded by the European Commission. 